\title{
Article \\ Structural, Electronic, and Physical Properties of a New Layered Cr-Based Oxyarsenide $\mathrm{Sr}_{2} \mathrm{Cr}_{2} \mathrm{AsO}_{3}$
}

\author{
Yi-Qiang Lin ${ }^{1}$, Hao Jiang ${ }^{1,2}$, Hua-Xun Li ${ }^{1}$, Shi-Jie Song ${ }^{1}$, Si-Qi Wu ${ }^{1}$, Zhi Ren ${ }^{3}$ and Guang-Han Cao ${ }^{1,4, *(D)}$ \\ 1 Department of Physics, Zhejiang University, Hangzhou 310027, China; yiqianglin@zju.edu.cn (Y.-Q.L.); \\ jialay@zju.edu.cn (H.J.); lihuaxun@zju.edu.cn (H.-X.L.); 11936028@zju.edu.cn (S.-J.S.); \\ sqwu@zju.edu.cn (S.-Q.W.) \\ 2 School of Physics and Optoelectronics, Xiangtan University, Xiangtan 411105, China \\ 3 School of Science, Westlake Institute for Advanced Study, Westlake University, Hangzhou 310064, China; \\ renzhi@westlake.edu.cn \\ 4 Zhejiang Province Key Laboratory of Quantum Technology and Devices, Interdisciplinary Center for \\ Quantum Information and State Key Lab of Silicon Materials, Zhejiang University, Hangzhou 310027, China \\ * Correspondence: ghcao@zju.edu.cn
}

check for updates

Citation: Lin, Y.-Q.; Jiang, H.; Li, H.-X.; Song, S.-J.; Wu, S.-Q.; Ren, Z.; Cao, G.-H. Structural, Electronic, and Physical Properties of a New Layered Cr-Based Oxyarsenide $\mathrm{Sr}_{2} \mathrm{Cr}_{2} \mathrm{AsO}_{3}$. Materials 2022, 15, 802. https:// doi.org/10.3390/ma15030802

Academic Editor: Andres Sotelo

Received: 8 December 2021

Accepted: 17 January 2022

Published: 21 January 2022

Publisher's Note: MDPI stays neutral with regard to jurisdictional claims in published maps and institutional affiliations.

Copyright: (C) 2022 by the authors. Licensee MDPI, Basel, Switzerland. This article is an open access article distributed under the terms and conditions of the Creative Commons Attribution (CC BY) license (https:// creativecommons.org/licenses/by/ $4.0 /)$.

\begin{abstract}
We report synthesis, crystal structure, and physical properties of $\mathrm{Sr}_{2} \mathrm{Cr}_{2} \mathrm{AsO}_{3}$. The new compound crystallizes in a $\mathrm{Sr}_{2} \mathrm{GaO}_{3} \mathrm{CuS}$-type structure with two distinct $\mathrm{Cr}$ sites, $\mathrm{Cr}(1)$ in the perovskite-like block layers of " $\mathrm{Sr}_{3} \mathrm{Cr}_{2} \mathrm{O}_{6}$ " and $\mathrm{Cr}(2)$ in the $\mathrm{ThCr}_{2} \mathrm{Si}_{2}$-type layers of " $\mathrm{SrCr}_{2} \mathrm{As}_{2}$ ". An inter-block-layer charge transfer is explicitly evidenced, which dopes electrons in the $\mathrm{CrO}_{2}$ planes and simultaneously dopes holes into the CrAs layers. Measurements of electrical resistivity, magnetization, and specific heat, in combination with density-functional theoretical calculations, indicate that the title material is an antiferromagnetic metal. The $\mathrm{Cr}(2)$ magnetic moments in the CrAs layers order at $420 \mathrm{~K}$, while the $\mathrm{Cr}(1)$ spins in the $\mathrm{CrO}_{2}$ planes show quasi-two-dimensional magnetism with long-range ordering below $80 \mathrm{~K}$. Both Néel temperatures are significantly reduced, compared with those of the cousin material $\mathrm{Sr}_{2} \mathrm{Cr}_{3} \mathrm{As}_{2} \mathrm{O}_{2}$, probably due to the intrinsic charge-carrier doping. Complex re-entrant magnetic transitions with a huge magnetic hysteresis were observed at low temperatures.
\end{abstract}

Keywords: Cr-based oxyarsenide; physical properties; DFT calculations; antiferromagnetism; interlayer charge transfer

\section{Introduction}

The discoveries of superconductivity in $\mathrm{CrAs}$ [1,2] at high pressures and, later in quasione-dimensional $A_{2} \mathrm{Cr}_{3} \mathrm{As}_{3}(A=\mathrm{K}, \mathrm{Rb}, \mathrm{Cs})$ at ambient pressure [3-5], motivate the research interest in other Cr-based materials [6-16]. Of particular interest are those with CrAs layers [17-20], which resemble the FeAs layers in iron-based superconductors [21]. Similar to the parent compounds of iron-based superconductors, these CrAs-layer based materials, such as $\mathrm{BaCr}_{2} \mathrm{As}_{2}$ [18] and $\mathrm{LaCrAsO}$ [20], also show antiferromagnetic (AFM) order and metallic conduction. Theoretical studies [6-8] suggest possible superconductivity in doped $\mathrm{BaCr}_{2} \mathrm{As}_{2}$ and LaCrAsO. Notably, the Néel temperatures are as high as $\sim 600 \mathrm{~K}$ (see Table 1), suggesting a large magnetic exchange interaction. If the AFM order can be suppressed, according to the common features of unconventional superconductivity [22], one expects possible high-temperature superconductivity in the class of Cr-based materials. In this context, explorations for additional materials with CrAs layers are of significance [23-26].

In 2015, the present authors [23] succeeded in synthesizing a Cr-based oxyarsenide $\mathrm{Sr}_{2} \mathrm{Cr}_{3} \mathrm{As}_{2} \mathrm{O}_{2}$. Structurally, the compound can be viewed as an intergrowth of $\mathrm{ThCr}_{2} \mathrm{Si}_{2}{ }^{-}$ type $\mathrm{SrCr}_{2} \mathrm{As}_{2}$ and perovskite-like infinite-layer " $\mathrm{SrCrO}_{2}$ " [27], thus bearing both CrAs layers and $\mathrm{CrO}_{2}$ planes. The material was demonstrated to be an AFM correlated metal. Later, the neutron diffraction study [28] revealed that the magnetic moments of $\mathrm{Cr}(1)$ (in 
the $\mathrm{CrO}_{2}$ planes) and $\mathrm{Cr}(2)$ (in the CrAs layers) are 3.10(6) $\mu_{\mathrm{B}}$ and 2.19(4) $\mu_{\mathrm{B}}$, respectively. The $\mathrm{Cr}(1)$ spins form a $\mathrm{La}_{2} \mathrm{CuO}_{4}$-like AFM order at $291 \mathrm{~K}$, and the $\mathrm{Cr}(2)$ moments show a C-type (Néel-type antiferromagnetism in the $a b$ plane and ferromagnetism along the $c$ axis) AFM order below $590 \mathrm{~K}$.

Table 1. Comparison of structural (at room temperature) and physical properties of the compounds with $\mathrm{CrAs}$ layers and / or $\mathrm{CrO}_{2}$ planes. $h_{\mathrm{CrAs}}$ denotes the As height from the $\mathrm{Cr}$ plane. $\alpha_{\mathrm{As}}-\mathrm{Cr}-\mathrm{As}$ is the As-Cr-As bond angle along $a$ or $b$ direction. BVS is the bond valence sum of $\mathrm{Cr}(1)$ coordinated by five oxygen atoms. $T_{\mathrm{N} 1}$ and $T_{\mathrm{N} 2}$ are the antiferromagnetic transition temperatures associated with $\mathrm{Cr}(1)$ and $\mathrm{Cr}(2)$, respectively, and $\mu_{\mathrm{Cr} 1}$ and $\mu_{\mathrm{Cr} 2}$ are their saturation magnetic moments. The symbol "-" represents that those data are not available.

\begin{tabular}{|c|c|c|c|c|c|c|c|c|c|c|c|}
\hline Compounds & $a(\AA)$ & $c(\AA ̊)$ & $c / a$ & $h_{\mathrm{CrAs}}(\AA)$ & $\begin{array}{c}\alpha_{\mathrm{As}-\mathrm{Cr}-\mathrm{As}} \\
\left({ }^{\circ}\right)\end{array}$ & BVS & $T_{\mathrm{N} 1}(\mathrm{~K})$ & $\mu_{\mathrm{Cr} 1}\left(\mu_{\mathrm{B}}\right)$ & $T_{\mathrm{N} 2}(\mathrm{~K})$ & $\mu_{\mathrm{Cr} 2}\left(\mu_{\mathrm{B}}\right)$ & Refs. \\
\hline $\mathrm{BaCr}_{2} \mathrm{As}_{2}$ & $3.9678(4)$ & $13.632(3)$ & 3.436 & 1.513 & 105.3 & - & - & - & - & - & [18] \\
\hline $\mathrm{BaCr}_{2} \mathrm{As}_{2}$ & 3.9667 & 13.6214 & 3.434 & 1.512 & 105.4 & - & - & - & 580 & 1.9 & [9] \\
\hline $\mathrm{SrCr}_{2} \mathrm{As}_{2}$ & $3.918(3)$ & $13.05(1)$ & 3.331 & 1.449 & 107.0 & - & - & - & 590 [11] & $1.9(1)$ & [17] \\
\hline $\mathrm{EuCr}_{2} \mathrm{As}_{2}$ & $3.893(2)$ & $12.872(2)$ & 3.306 & 1.455 & 106.5 & - & - & - & 680 [29] & $1.7(4)$ & [19] \\
\hline $\mathrm{LaCrAsO}$ & $4.0412(3)$ & $8.9863(7)$ & 2.224 & 1.460 & 108.3 & - & - & - & $>300$ & - & [20] \\
\hline $\mathrm{Sr}_{2} \mathrm{Cr}_{3} \mathrm{As}_{2} \mathrm{O}_{2}$ & $4.0079(1)$ & $18.8298(3)$ & 4.698 & 1.505 & 106.2 & 2.10 & 291 & $\begin{array}{c}2.97 \\
\text { (calc.) }\end{array}$ & - & $\begin{array}{c}2.59 \\
\text { (calc.) }\end{array}$ & [27] \\
\hline $\mathrm{Sr}_{2} \mathrm{Cr}_{3} \mathrm{As}_{2} \mathrm{O}_{2}$ & $4.00671(6)$ & $18.8310(5)$ & 4.700 & 1.503 & 106.2 & 1.90 & 291 & $3.10(6)$ & 590 & $2.19(4)$ & [28] \\
\hline $\mathrm{Sr}_{2} \mathrm{Cr}_{3} \mathrm{As}_{2} \mathrm{O}_{2}$ & $4.00800(2)$ & $18.8214(1)$ & 4.696 & 1.505 & 106.4 & 1.90 & 330 & $3.34(1)$ & 600 & $2.68(1)$ & [25] \\
\hline $\mathrm{Ba}_{2} \mathrm{Cr}_{3} \mathrm{As}_{2} \mathrm{O}_{2}$ & $4.05506(2)$ & $20.5637(1)$ & 5.071 & 1.478 & 107.8 & 1.79 & 230 & $3.30(1)$ & 465 & $2.23(1)$ & [25] \\
\hline $\mathrm{Sr}_{2} \mathrm{CrFeAsO}_{3}$ & $3.9112(1)$ & $15.7905(3)$ & 4.037 & - & - & 2.69 & 31 & - & - & - & [30] \\
\hline $\mathrm{Sr}_{2} \mathrm{CrFeAsO}_{3}$ & 3.918 & 15.683 & 4.003 & - & - & 2.93 & - & - & - & - & [31] \\
\hline $\mathrm{Sr}_{2} \mathrm{ScCrAsO}_{3}$ & $4.043(9)$ & $16.038(1)$ & 3.967 & 1.498 & 106.9 & - & - & - & - & - & [26] \\
\hline $\mathrm{Sr}_{2} \mathrm{Cr}_{2} \mathrm{AsO}_{3}$ & $3.9087(2)$ & $16.0481(4)$ & 4.300 & 1.560 & 102.8 & 2.52 & 80 & $\begin{array}{c}2.52 \\
\text { (calc.) }\end{array}$ & 420 & $\begin{array}{c}2.41 \\
\text { (calc.) }\end{array}$ & $\begin{array}{l}\text { This } \\
\text { work }\end{array}$ \\
\hline
\end{tabular}

We note that the perovskite-like block layer $A_{3} \mathrm{Cr}_{2} \mathrm{O}_{6}(A=\mathrm{Sr}$, Ba) can be intergrown with the $\mathrm{ThCr}_{2} \mathrm{Si}_{2}$-type $A M_{2} \mathrm{As}_{2}(M=\mathrm{Fe}, \mathrm{Co})$ [30,31], forming a $\mathrm{Sr}_{2} \mathrm{GaO}_{3} \mathrm{CuS}$-type structure [32]. This suggests the possibility of synthesis of an analogous $\mathrm{Cr}$-based oxyarsenide, $\mathrm{Sr}_{2} \mathrm{Cr}_{2} \mathrm{AsO}_{3}$, which contains alternating layers of " $\mathrm{Sr}_{3} \mathrm{Cr}_{2} \mathrm{O}_{6}$ " and " $\mathrm{SrCr}_{2} \mathrm{As}_{2}$ " (see the inset of Figure 1). Notably, the target structure bears distinct $\mathrm{Cr}$ valence in different block layers (namely, $\mathrm{Cr}^{3+}$ in the perovskite-like $A_{3} \mathrm{Cr}_{2} \mathrm{O}_{6}$ and $\mathrm{Cr}^{2+}$ in $\mathrm{SrCr}_{2} \mathrm{As}_{2}$ ), in contrast to the case in $\mathrm{Sr}_{2} \mathrm{Cr}_{3} \mathrm{As}_{2} \mathrm{O}_{2}$ where the valences of $\mathrm{Cr}(1)$ and $\mathrm{Cr}(2)$ are both 2+. An inter-block-layer charge transfer is thus anticipated, which effectively dopes holes in the CrAs layers. This makes $\mathrm{Sr}_{2} \mathrm{Cr}_{2} \mathrm{AsO}_{3}$ particularly interesting.

In this paper, we report the synthesis, crystal structure, and physical properties of $\mathrm{Sr}_{2} \mathrm{Cr}_{2} \mathrm{AsO}_{3}$ (this phase was identified using electron microscopy as an impurity (1.3\%) in the synthesized sample of $\mathrm{Sr}_{2} \mathrm{Cr}_{3} \mathrm{As}_{2} \mathrm{O}_{2}$ [25]). The crystal structure is determined by the Rietveld refinement, from which the bond-valence sum of $\mathrm{Cr}(1)$ is calculated to be +2.52 . The result indicates a mixed valence for $\mathrm{Cr}(1)$, suggesting an inter-block-layer charge transfer. The charge transfer is also supported by the $\mathrm{Cr}(1)$ effective moment from the magnetic measurement and the Bader charge analysis on the basis of density-functional-theory (DFT) calculations. The magnetic measurement reveals that the Néel temperatures in the CrAs layers and the $\mathrm{CrO}_{2}$ planes are $T_{\mathrm{N} 2}=420 \mathrm{~K}$ and $T_{\mathrm{N} 1} \approx 80 \mathrm{~K}$, which are remarkably reduced, in comparison with the counterparts ( $\sim 600 \mathrm{~K}$ and $\sim 300 \mathrm{~K}$, respectively) in $\mathrm{Sr}_{2} \mathrm{Cr}_{3} \mathrm{As}_{2} \mathrm{O}_{2}$. The suppression of the Néel temperatures is probably due to the charge-carrier dopings, originating from the interlayer charge transfer. Complex re-entrant magnetic transitions with a huge magnetic hysteresis were observed at low temperatures. The magnetic ground state is studied by the DFT-based first-principles calculations. 


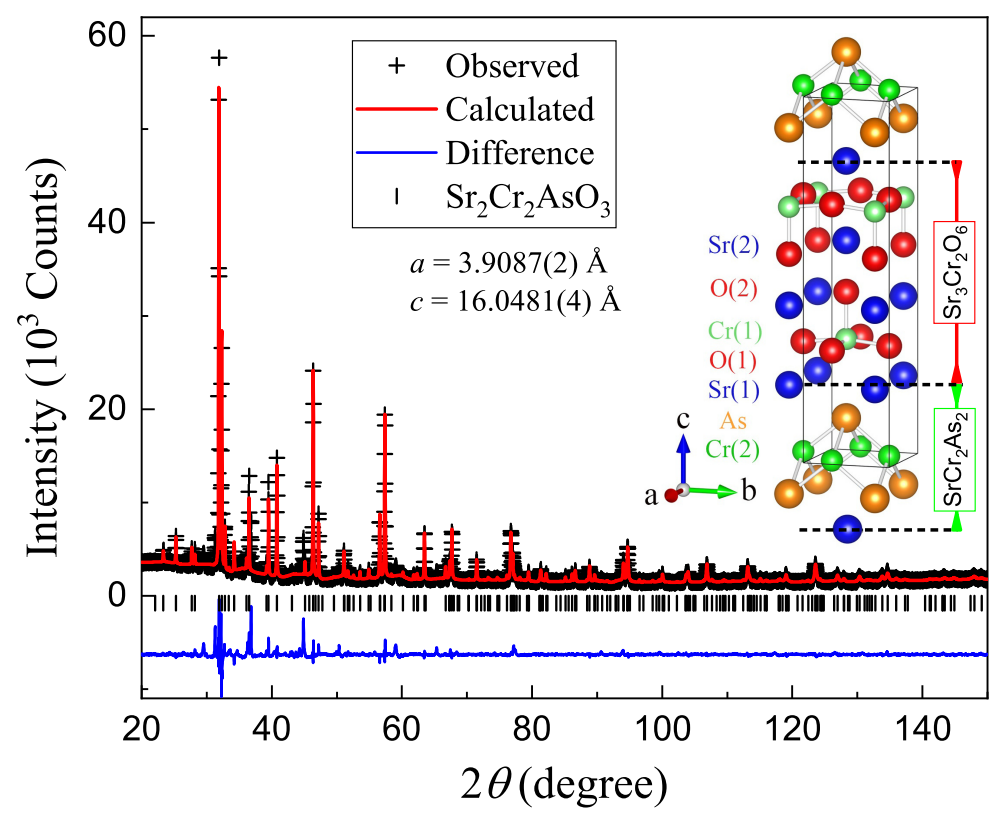

Figure 1. Powder $\mathrm{X}$-ray diffraction at room temperature and its Rietveld refinement profile of $\mathrm{Sr}_{2} \mathrm{Cr}_{2} \mathrm{AsO}_{3}$. The inset shows the crystal structure consisting of block layers of $\mathrm{Sr}_{3} \mathrm{Cr}_{2} \mathrm{O}_{6}$ and $\mathrm{SrCr}_{2} \mathrm{As}_{2}$.

\section{Experimental Methods}

The $\mathrm{Sr}_{2} \mathrm{Cr}_{2} \mathrm{AsO}_{3}$ polycrystalline sample was synthesized by solid-state reactions in vacuum. The source materials were Sr pieces (99\%), As pieces (99.999\%), Cr powders (99.99\%), and $\mathrm{Cr}_{2} \mathrm{O}_{3}$ powders (99.97\%). Mixtures of these raw materials with the nearly nominal composition (the oxygen content is reduced by $6 \%$ to compensate the slight oxidation in the reactive $\mathrm{Sr}$ pieces) were put into an alumina crucible, sealed in an evacuated silica tube, then calcined in a muffle furnace at $800{ }^{\circ} \mathrm{C}$ for $24 \mathrm{~h}$. After cooling, the sample was thoroughly ground for homogenization and pressed into a pellet in a glove box filled with argon gas. The pellet was also loaded an alumina crucible, sealed in an evacuated silica tube, and then heated to $1100{ }^{\circ} \mathrm{C}$, holding at this temperature for $40 \mathrm{~h}$. Finally, the sample was allowed to cool down by switching off the furnace.

The X-ray diffraction (XRD) was performed at room temperature using a PANalytical X-ray diffractometer with $\mathrm{Cu}-\mathrm{K}_{\alpha 1}$ radiation. The crystal structure was refined by the Rietveld analysis using FullProf suite [33]. The electrical resistivity and specific heat were measured with a quantum design physical property measurement system (PPMS). The magnetic properties were measured by a quantum design magnetic property measurement system (MPMS-3). The measurement was allowed at temperatures up to $700 \mathrm{~K}$ by employing a high-temperature option.

The first-principles calculations were done within the generalized gradient approximation [34] by using the Vienna Ab-initio Simulation Package (VASP) [35]. The experimental crystal structure was used for the calculations. The plane-wave basis energy cutoff was chosen to be $550 \mathrm{eV}$. A $10 \times 10 \times 5$ Г-centered K-mesh was used for the density-of-states (DOS) calculations.

\section{Results and Discussion}

\subsection{Crystal Structure}

Figure 1 shows the XRD pattern of the as-prepared polycrystalline sample of $\mathrm{Sr}_{2} \mathrm{Cr}_{2} \mathrm{AsO}_{3}$. All the strong $X R D$ reflections can be indexed using a primitive tetragonal unit cell with $a \approx 3.91 \AA$ and $c \approx 16.05 \AA$. Some unindexed weak peaks probably come from the unreacted $\mathrm{CrAs}$ and $\mathrm{SrO}$, while the others cannot be identified with known phases. The lattice constants are very close to those of the analogous compound $\mathrm{Sr}_{2} \mathrm{CrFeAsO}_{3}[30,31]$, suggesting the formation of the target phase. Indeed, the XRD data can be successfully 
refined with the $\mathrm{Sr}_{2} \mathrm{GaO}_{3} \mathrm{CuS}$-type structure model [32]. The $R$ factors of the refinement are $R_{\mathrm{B}}=4.65 \%$ and $R_{\mathrm{wp}}=8.21 \%$. Furthermore, the Goodness-of-fit index is 3.8. The refined crystallographic data are listed in Table 2.

Table 2. Room-temperature crystallographic data of $\mathrm{Sr}_{2} \mathrm{Cr}_{2} \mathrm{AsO}_{3}$ with lattice parameters of $a=3.9087(2) \AA$ and $c=16.0481(4) \AA$, and with space group P4/nmm (No. 129).

\begin{tabular}{lccccc}
\hline Atoms & Sites & $\boldsymbol{x}$ & $\boldsymbol{y}$ & $\boldsymbol{z}$ & $\boldsymbol{B}\left(\AA^{\mathbf{2}}\right)$ \\
\hline $\mathrm{Sr}(1)$ & $2 c$ & 0.75 & 0.75 & $0.1997(3)$ & 0.56 \\
$\mathrm{Sr}(2)$ & $2 c$ & 0.75 & 0.75 & $0.4177(3)$ & 0.90 \\
$\mathrm{Cr}(1)$ & $2 c$ & 0.25 & 0.25 & $0.3117(4)$ & 0.81 \\
$\mathrm{Cr}(2)$ & $2 a$ & 0.25 & 0.75 & 0 & 0.61 \\
$\mathrm{As}$ & $2 c$ & 0.25 & 0.25 & $0.0973(3)$ & 0.36 \\
$\mathrm{O}(1)$ & $4 f$ & 0.25 & 0.75 & $0.2945(10)$ & 1.01 \\
$\mathrm{O}(2)$ & $2 c$ & 0.25 & 0.25 & $0.4411(16)$ & 0.73 \\
\hline
\end{tabular}

As shown in the inset of Figure 1, the crystal structure of $\mathrm{Sr}_{2} \mathrm{Cr}_{2} \mathrm{AsO}_{3}$ can be viewed as an alternating stacking of $\mathrm{Sr}_{3} \mathrm{Cr}_{2} \mathrm{O}_{6}$ and $\mathrm{SrCr}_{2} \mathrm{As}_{2}$ block layers along the $c$ direction. According to the block-layer model for an intergrowth structure [36], inter-block-layer charge transfer and lattice match are the two major factors for the stabilization. Furthermore, the lattice constant $a$ is mainly determined by the structural block with a larger stiffness. In Table 1, one sees that the $a$ axis of $\mathrm{Sr}_{2} \mathrm{Cr}_{2} \mathrm{AsO}_{3}$ is close to that of $\mathrm{Sr}_{2} \mathrm{CrFeAsO}_{3}$, but significantly smaller than those of $\mathrm{Sr}_{2} \mathrm{Cr}_{3} \mathrm{As}_{2} \mathrm{O}_{2}$ and $\mathrm{Sr}_{2} \mathrm{ScCrAsO}_{3}$. The result suggests that the perovskite-like block layers of $\mathrm{Sr}_{3} \mathrm{Cr}_{2} \mathrm{O}_{6}, \mathrm{SrCrO}_{2}$, and $\mathrm{Sr}_{3} \mathrm{Sc}_{2} \mathrm{O}_{6}$ are harder, which dominantly determine the $a$ axis. Note that the $a$ axis of $\mathrm{Sr}_{2} \mathrm{Cr}_{2} \mathrm{AsO}_{3}$ is also close to that of $\mathrm{SrCr}_{2} \mathrm{As}_{2}$, which indicates a very good lattice match between the two building blocks.

There are two distinct crystallographic $\mathrm{Cr}$ sites, $\mathrm{Cr}(1)$ and $\mathrm{Cr}(2)$, in the block layers of $\mathrm{Sr}_{3} \mathrm{Cr}_{2} \mathrm{O}_{6}$ and $\mathrm{SrCr}_{2} \mathrm{As}_{2}$, respectively. The former is pyramidally coordinated by five oxygen atoms with a formal valence of +3 , and the latter is bonded tetrahedrally by four As atoms with a formal valence of +2 . To evaluate the possible inter-block-layer charge transfer, we calculate the bond valence sum (BVS) [37] of $\mathrm{Cr}(1)$ (note that the BVS concept does not apply for $\mathrm{Cr}(2)$ because of the dominant covalence of the $\mathrm{Cr}(2)-$ As bonding). The calculated BVS value is calculated to be +2.52 , suggesting a mixed valence for $\mathrm{Cr}(1)$. In comparison, the Cr-BVS value in $\mathrm{Sr}_{2} \mathrm{CrFeAsO}_{3}$ is 2.93 [31], and it is 1.9-2.1 in $\mathrm{Sr}_{2} \mathrm{Cr}_{3} \mathrm{As}_{2} \mathrm{O}_{2}[23,25,28$ ]. All these data conformably suggest an interlayer charge transfer between the two block layers, which primarily stabilizes the structure [36]. The interlayer charge transfer leads to electron doping in the $\mathrm{CrO}_{2}$ planes and hole doping in the CrAs layers. From Table 1, one sees that the As height (above the Cr plane) is exceptionally high and, correspondingly, the As-Cr-As bond angle along $a$ axis is exceptionally small. These structural changes may be associated with the effective hole doping in the CrAs layers.

\subsection{Electrical Resistivity}

The temperature dependence of resistivity, $\rho(T)$, for the $\mathrm{Sr}_{2} \mathrm{Cr}_{2} \mathrm{AsO}_{3}$ polycrystalline sample is shown in Figure 2. A typical metallic behavior shows up without any obvious anomaly below room temperature. Similar observations were observed in $\mathrm{BaCr}_{2} \mathrm{As}_{2}[9,18]$ and $\mathrm{LaCrAsO}$ [20]. For $\mathrm{Sr}_{2} \mathrm{ScCrAsO}_{3}$ and $\mathrm{Ba}_{2} \mathrm{ScCrAsO}_{3}$ [26], which contain insulating block layers of $\mathrm{Sr}_{3} \mathrm{Sc}_{2} \mathrm{O}_{6}$ and $\mathrm{Ba}_{3} \mathrm{Sc}_{2} \mathrm{O}_{6}$, respectively, the $\rho(T)$ behaviors are basically metallic. These results suggest that the $\mathrm{CrAs}$ layers are mainly responsible for the metallic conduction. 


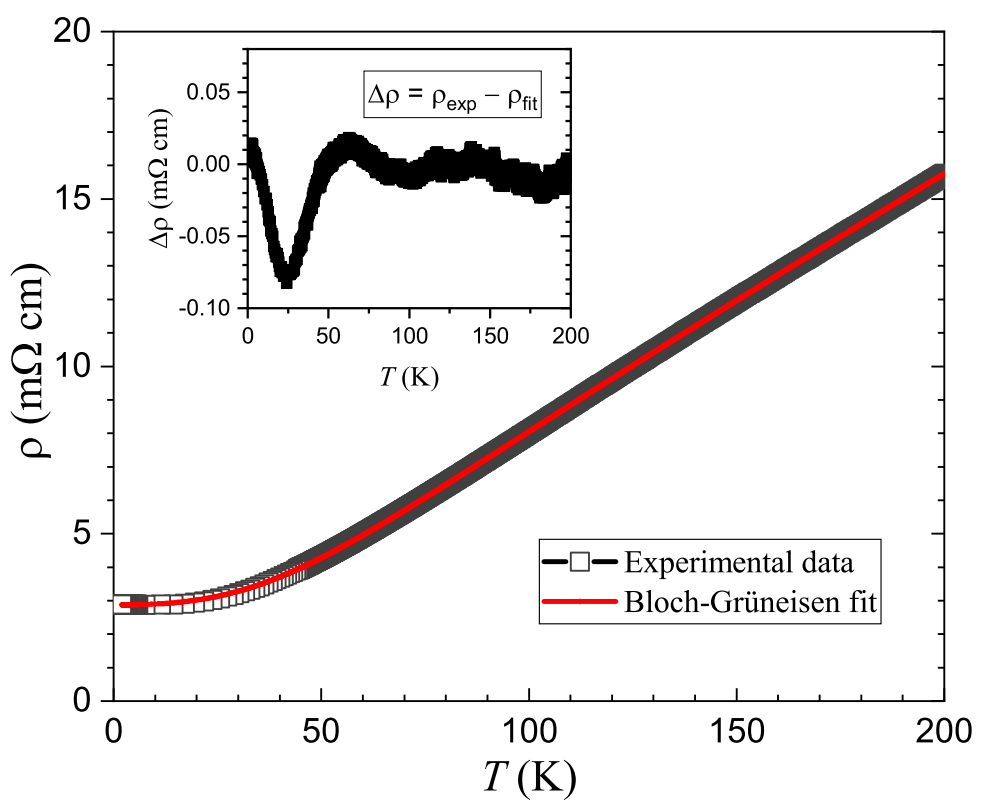

Figure 2. Temperature dependence of electrical resistivity of the $\mathrm{Sr}_{2} \mathrm{Cr}_{2} \mathrm{AsO}_{3}$ polycrystalline sample. The solid line is a fit with the extended Bloch-Grüneisen formula (see the text). The inset shows the difference, $\Delta \rho$, between the experimental and fitted data. The drop in $\Delta \rho$ by $\sim 3 \%$ below $70 \mathrm{~K}$ suggests reduction of the magnetic scattering by $\mathrm{Cr}(1)$ spins.

As treated previously [23], the $\rho(T)$ data were fitted with the extended Bloch-Grüneisen formula,

$$
\rho(T)=\rho_{0}+A\left(\frac{T}{\Theta_{R}}\right)^{n} \int_{0}^{\Theta_{R} / T} \frac{x^{n}}{\left(e^{x}-1\right)\left(1-e^{-x}\right)} d x,
$$

where $n$ is a fitting parameter characterizing the conduction electron scattering [38-40]. The data fitting yields $n=2.58, \Theta_{R}=303 \mathrm{~K}$, and $\rho_{0}=2.87 \mathrm{~m} \Omega \mathrm{cm}$. One sees that the $n$ value lies in between 2 and 3, implying both electron-electron and electron-magnon scattering $[39,41]$. To reveal the possible change in magnetic scattering, we made the subtraction of fitted data from the experimental ones. The result is plotted in the inset of Figure 2. One sees a broad dip (resistivity decreased by $\sim 3 \%$ ) below $\sim 70 \mathrm{~K}$. This slight response of resistivity could be associated with the magnetic ordering at the $\mathrm{Cr}(1)$ site (see below).

\subsection{Magnetic Properties}

Figure 3 shows the temperature dependence of magnetic susceptibility, $\chi(T)$, for $\mathrm{Sr}_{2} \mathrm{Cr}_{2} \mathrm{AsO}_{3}$. The data show a Curie-Weiss (CW) behavior at high temperatures up to $700 \mathrm{~K}$. The $\mathrm{CW}$ behavior is reasonably attributed to the contribution of $\mathrm{Cr}(1)$ in the $\mathrm{Sr}_{3} \mathrm{Cr}_{2} \mathrm{O}_{6}$ layers, because the $\chi(T)$ of materials with $\mathrm{CrAs}$ layers only, such as $\mathrm{BaCr}_{2} \mathrm{As}_{2}$ [9], $\mathrm{LaCrAsO}$ [20], and $\mathrm{Sr}_{2} \mathrm{ScCrAsO}_{3}$ [26], is not CW like. The data fitting in the temperature range from $314 \mathrm{~K}$ to $700 \mathrm{~K}$ by using the extended $\mathrm{CW}$ law, $\chi=\chi_{0}+C /\left(T+\theta_{\mathrm{CW}}\right)$, yields $\chi_{0}=3.15 \times 10^{-4} \mathrm{emu} \mathrm{mol}^{-1}, \mathrm{C}=2.13 \mathrm{emu} \mathrm{K} \mathrm{mol}^{-1}$, and $\theta_{\mathrm{CW}}=352 \mathrm{~K}$. The positive CW temperature indicates dominant antiferromagnetic interactions among the $\mathrm{Cr}(1)$ spins. The fitted parameter $C$ gives rises to an effective moment for $\operatorname{Cr}(1)$ atoms, $\mu_{\text {eff }}^{\mathrm{Cr} 1}=4.13 \mu_{\mathrm{B}}$, which lies in between the expected values of high-spin $\mathrm{Cr}^{3+}\left(3.87 \mu_{\mathrm{B}}\right)$ and high-spin $\mathrm{Cr}^{2+}$ $\left(4.90 \mu_{\mathrm{B}}\right)$. The result suggests local-moment and mixed-valence scenarios for $\mathrm{Cr}(1)$ atoms. The latter arises from the interlayer charge transfer as demonstrated above. 


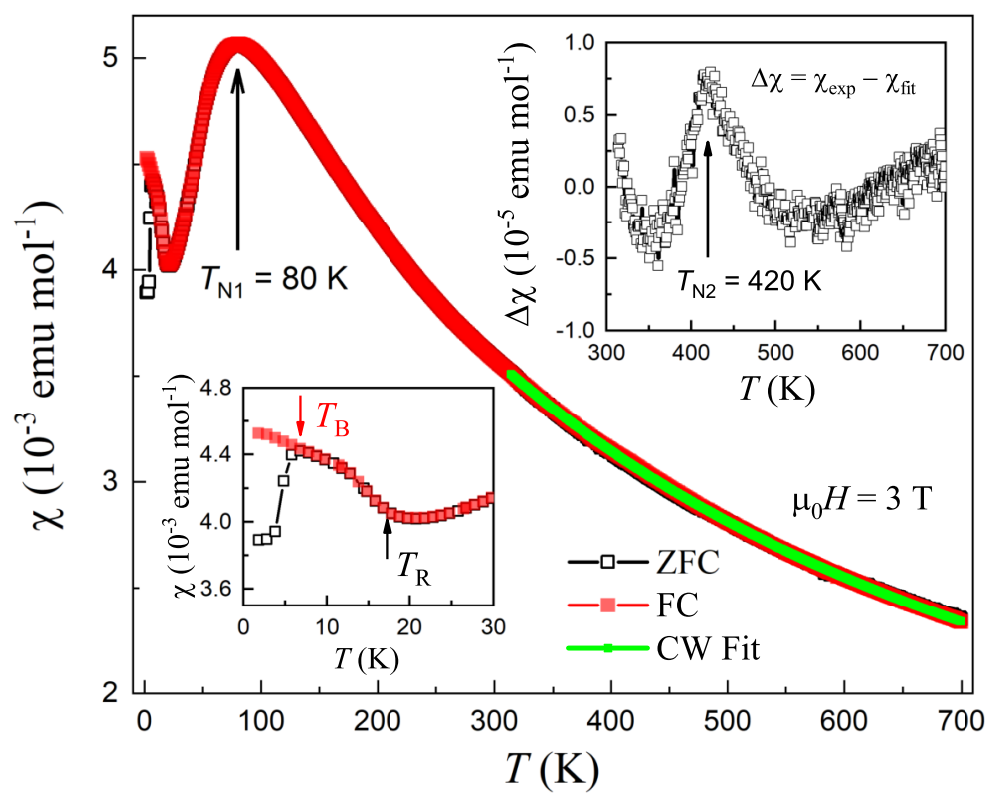

Figure 3. Temperature dependence of magnetic susceptibility, $\chi(T)$, under an applied field of $\mu_{0} \mathrm{H}=3 \mathrm{~T}$ for $\mathrm{Sr}_{2} \mathrm{Cr}_{2} \mathrm{AsO}_{3}$. The green solid line is the Curie-Weiss (CW) fit. The upper inset plots the difference in $\chi$ between the experimental data and the fitted ones. The bottom inset shows the closeup of the $\chi(T)$ curves at low temperatures.

To detect the possible magnetic transition related to the $\mathrm{CrAs}$ layers in $\mathrm{Sr}_{2} \mathrm{Cr}_{2} \mathrm{AsO}_{3}$, we treated the $\mathrm{CW}$ magnetism as a background, and made a subtraction of the $\mathrm{CW}$-fit data from the experimental $\chi(T)$ data. As is seen in the upper-right inset of Figure 3, a drop of $\chi$ shows up at $420 \mathrm{~K}$, indicating an AFM transition. Here we note that the Néel temperature of the $\mathrm{Cr}(2)$ sublattice, $\mathrm{T}_{\mathrm{N} 2}$, is remarkably reduced, compared with those of other CrAs-layer based materials including $\mathrm{SrCr}_{2} \mathrm{As}_{2}$ (see Table 1). Since the $a$ axes of $\mathrm{Sr}_{2} \mathrm{Cr}_{2} \mathrm{AsO}_{3}$ and $\mathrm{SrCr}_{2} \mathrm{As}_{2}$ are comparable, the reduction of $T_{\mathrm{N} 2}$ in $\mathrm{Sr}_{2} \mathrm{Cr}_{2} \mathrm{AsO}_{3}$ is arguably attributed to the hole-doping effect in the $\mathrm{CrAs}$ layers because of the interlayer charge transfer.

Now that the high-temperature $\mathrm{CW}$ behavior comes from the $\mathrm{Cr}(1)$-spin paramagnetism, the susceptibility drop below $T_{\mathrm{N} 1} \approx 80 \mathrm{~K}$ in Figure 3 is then ascribed to an AFM ordering in $\mathrm{Sr}_{3} \mathrm{Cr}_{2} \mathrm{O}_{6}$ block layers. The slight loss of resistivity below $\sim 70 \mathrm{~K}$ in Figure 2 can be understood in terms of reduction of magnetic scattering. The $T_{\mathrm{N} 1}$ value is remarkably lower than $\theta_{\mathrm{CW}}=352 \mathrm{~K}$, implying quasi-two-dimensional (quasi-2D) magnetism. Indeed, there is a broad hump above $T_{\mathrm{N} 1}$, reflecting quasi-2D AFM correlations/short-range order [42-45]. Similar behaviors also appear in $\mathrm{Sr}_{3} \mathrm{Cr}_{2} \mathrm{O}_{6}$-layer-bearing $\mathrm{Sr}_{2} \mathrm{CrO}_{3} \mathrm{FeAs}$ [31] and $\mathrm{Sr}_{2} \mathrm{CrO}_{3} \mathrm{CuS}$ [46]. Besides, the reduced $T_{\mathrm{N} 1}$ (in comparison with that of $\mathrm{Sr}_{2} \mathrm{Cr}_{3} \mathrm{As}_{2} \mathrm{O}_{2}[25,28]$ ) may be accounted for by the electron doping in the $\mathrm{CrO}_{2}$ planes.

Interestingly, there exist additional magnetic anomalies at lower temperatures, which are shown in the bottom-left inset of Figure 3. More data at varied magnetic fields are given in Figure 4 . One sees that, below $T_{\mathrm{N} 1}$, the magnetic susceptibility increases steeply with decreasing temperature at $T_{R}$, suggesting a re-entrant magnetic transition. With further decreasing temperature, the FC and ZFC data bifurcates at $T_{\mathrm{B}}$, and $\chi_{\mathrm{ZFC}}$ drops abruptly below $T_{B}$. The inset of Figure $4 \mathrm{~b}$ plots $T_{R}$ and $T_{B}$ as functions of magnetic field. It is clear that $T_{R}$ increases steadily with field, while $T_{B}$ decreases slowly. 

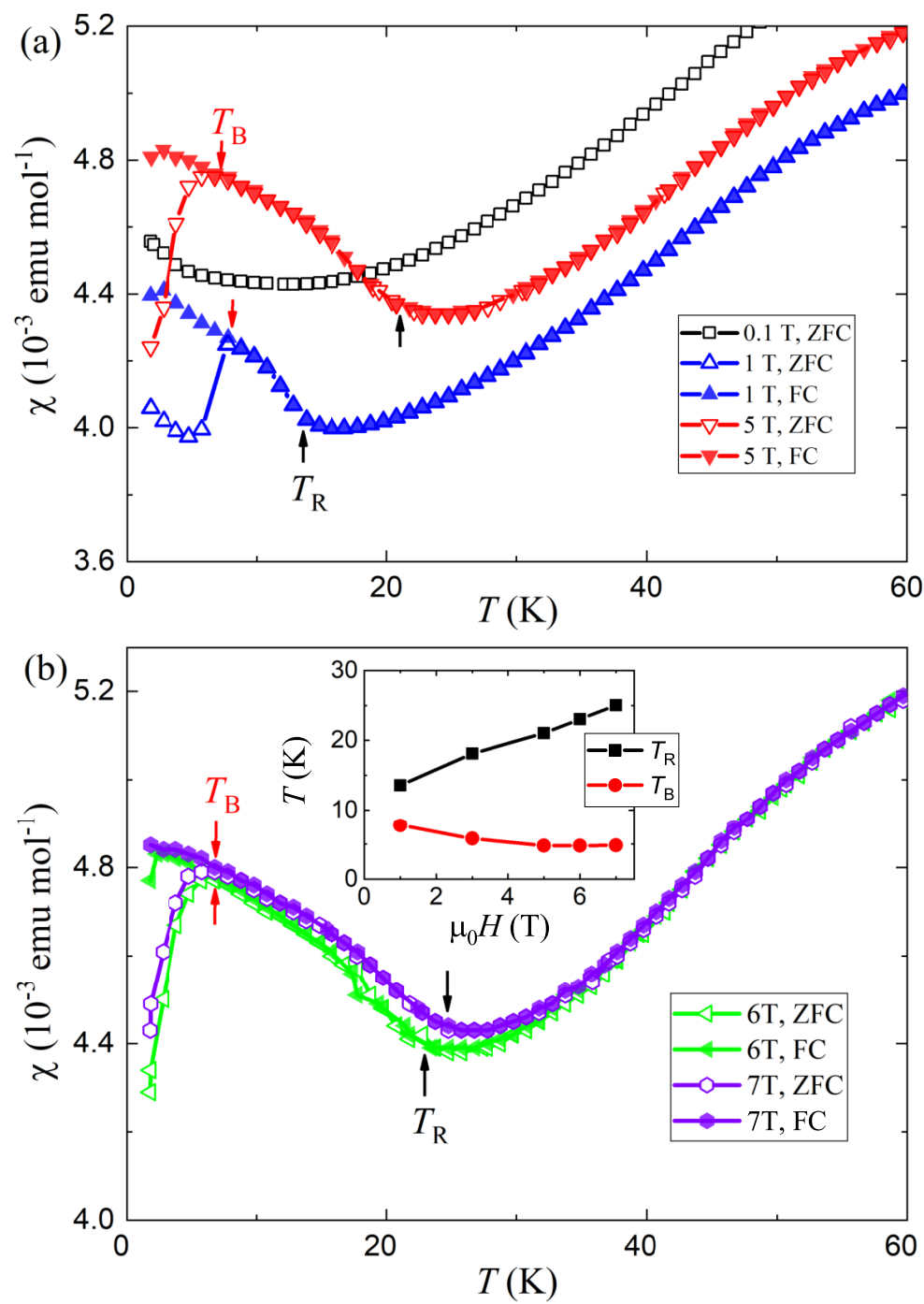

Figure 4. Temperature dependence of magnetic susceptibility for $\mathrm{Sr}_{2} \mathrm{Cr}_{2} \mathrm{AsO}_{3}$ at varied magnetic fields of $0.1,1,5$ (a), 6, and $7 \mathrm{~T}(\mathbf{b})$ in the field-cooling (FC) and zero-field-cooling (ZFC) measurement modes. The inset of $(\mathbf{b})$ shows the changes of $T_{R}$ and $T_{B}$ with the magnetic field.

In order to clarify the magnetic anomalies above, we carried out the measurements of isothermal magnetization, $M(H)$, by sweeping magnetic fields in a loop (i.e., $\mu_{0} H=0 \mathrm{~T} \rightarrow$ $6 \mathrm{~T} \rightarrow-6 \mathrm{~T} \rightarrow 6 \mathrm{~T})$. Figure 5 displays some selective $M(H)$ data. At first sight, $M$ seems to be linearly proportional to $H$ at varied temperatures from $2 \mathrm{~K}$ to $300 \mathrm{~K}$. On closer examination, however, a slight magnetic hysteresis can be found. To extract the hysteresis, we made a subtraction, $\Delta M=M-M_{\text {ref }}$, by employing a paramagnetic reference of $M_{\text {ref }}=41.5 \mathrm{H}$. As a result, an anomalous hysteresis shows up in the $\Delta M$ plot [Figure 5b]. In the low-field region, one sees a ferromagnetic-like magnetization with a coercive field of about $0.018 \mathrm{~T}(180 \mathrm{Oe})$. This reflects that the re-entrant magnetic transition at $T_{\mathrm{R}}$ induces a ferromagnetic component. Nevertheless, the "saturation" magnetization is only about $5 \mathrm{emu} / \mathrm{mol}$, equivalent to $\sim 10^{-3} \mu_{\mathrm{B}}$ per formula unit. Given the antiferromagnetic states in both $\mathrm{Cr}(2)$ and $\mathrm{Cr}(1)$ sublattices, then, the small-moment ferromagnetism is likely originated from the Cr-spin canting. The origin of the spin canting could be in relation with double exchange, as shown in the classical literature by de Gennes [47]. Notably, the magnetic hysteresis is huge, consistent with the bifurcation of magnetic susceptibility in FC and ZFC measurements under magnetic fields up to $\mu_{0} H=7 \mathrm{~T}$. Furthermore, the magnetic hysteresis does not form a loop when increasing field from -6 to $6 \mathrm{~T}$. This magnetic behavior is rarely seen. We conjecture that it is due to the complex magnetic structure and, in particular, 
in relation with the proximity of magnetic energy for different spin directions (see the DFT-based calculations below).

(a)
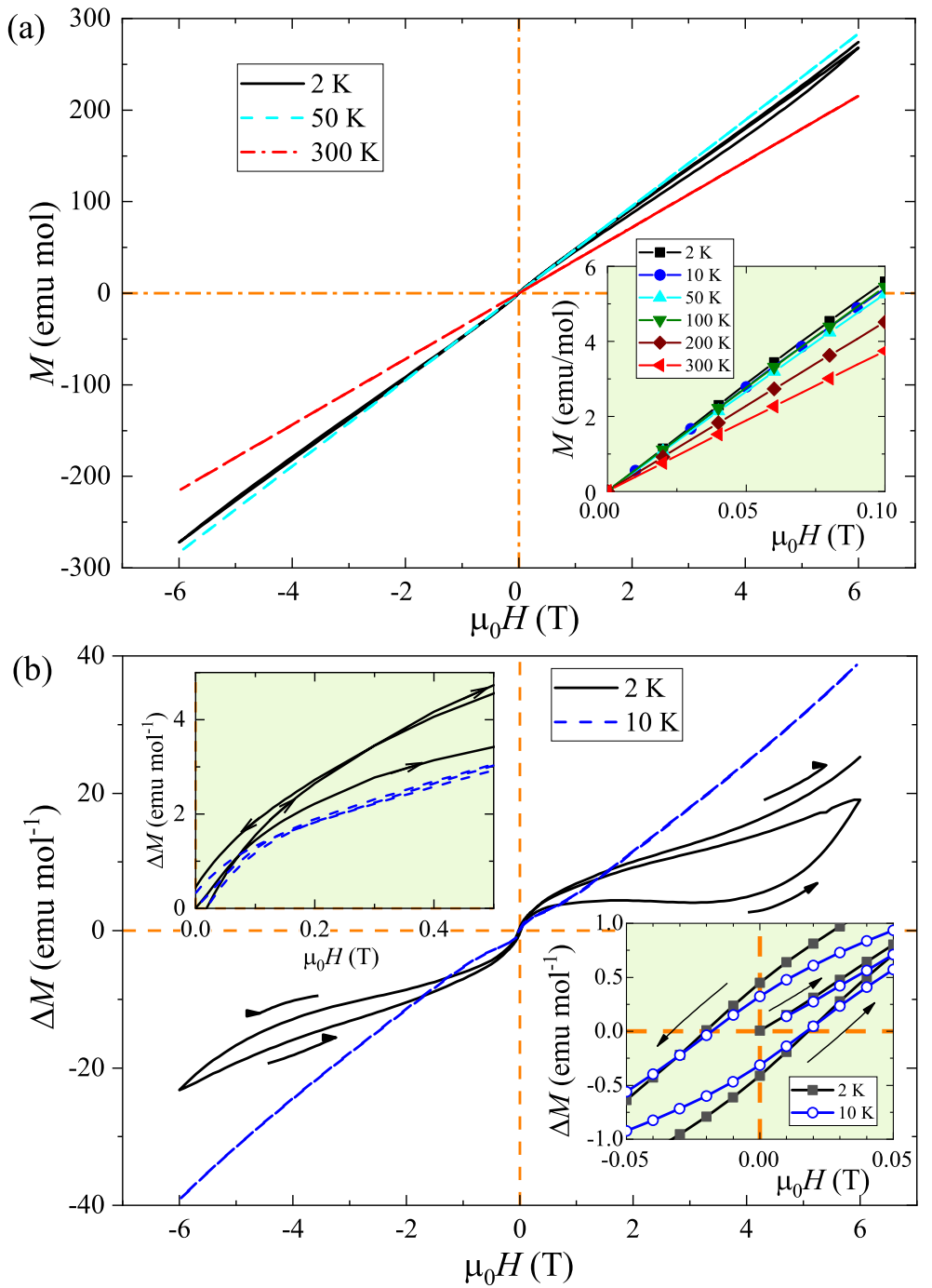

Figure 5. (a) Field dependence of magnetization at some selective temperatures for $\mathrm{Sr}_{2} \mathrm{Cr}_{2} \mathrm{AsO}_{3}$. Panel (b) shows the magnetization difference, $\Delta M=M-41.5 \mathrm{H}$, at 2 and $10 \mathrm{~K}$. All the insets are closeups for showing the details clearly.

\subsection{Specific Heat}

Figure 6 shows the temperature dependence of specific heat, $C(T)$, for $\mathrm{Sr}_{2} \mathrm{Cr}_{2} \mathrm{AsO}_{3}$. At first sight, there is no obvious anomaly below room temperature. That is to say, the AFM transition below $80 \mathrm{~K}$, manifested by the magnetic measurement above, is not associated with an abrupt change in entropy. This is actually consistent with the quasi-2D magnetism, in which magnetic correlations and short-range magnetic order exist at a wide temperature range around $T_{\mathrm{N} 1}$.

Let us first analyze the low-temperature $C(T)$ data. At such low temperatures below $5 \mathrm{~K}$, the lattice contribution well obeys Debye's $T^{3}$ law. Furthermore, the magnetic contributions can be ignored because $T \ll T_{\mathrm{N}}$. Therefore, the total specific heat can be formulated with $C(T)=\gamma T+\beta T^{3}$, where $\gamma$ is the electronic specific-heat coefficient. The upper inset of Figure 6 plots $C / T$ as a function of $T^{2}$ in the low temperature range from 2 to $5 \mathrm{~K}$. Indeed, one sees that $C / T$ is essentially linear with $T^{2}$. The linear fitting gives $\gamma=13.05 \mathrm{~mJ} \mathrm{~K}^{-2}$ $\mathrm{mol}^{-1}$ and $\beta=0.517 \mathrm{~mJ} \mathrm{~K}^{-4} \mathrm{~mol}^{-1}$. Using the formula $\Theta_{\mathrm{D}}=\left[(12 / 5) N R \pi^{4} / \beta\right]^{1 / 3}$, we 
obtain a Debye temperature of $311.0 \mathrm{~K}$. The $\Theta_{\mathrm{D}}$ value is rather close to $\Theta_{R}$ obtained from the fit of resistivity above.

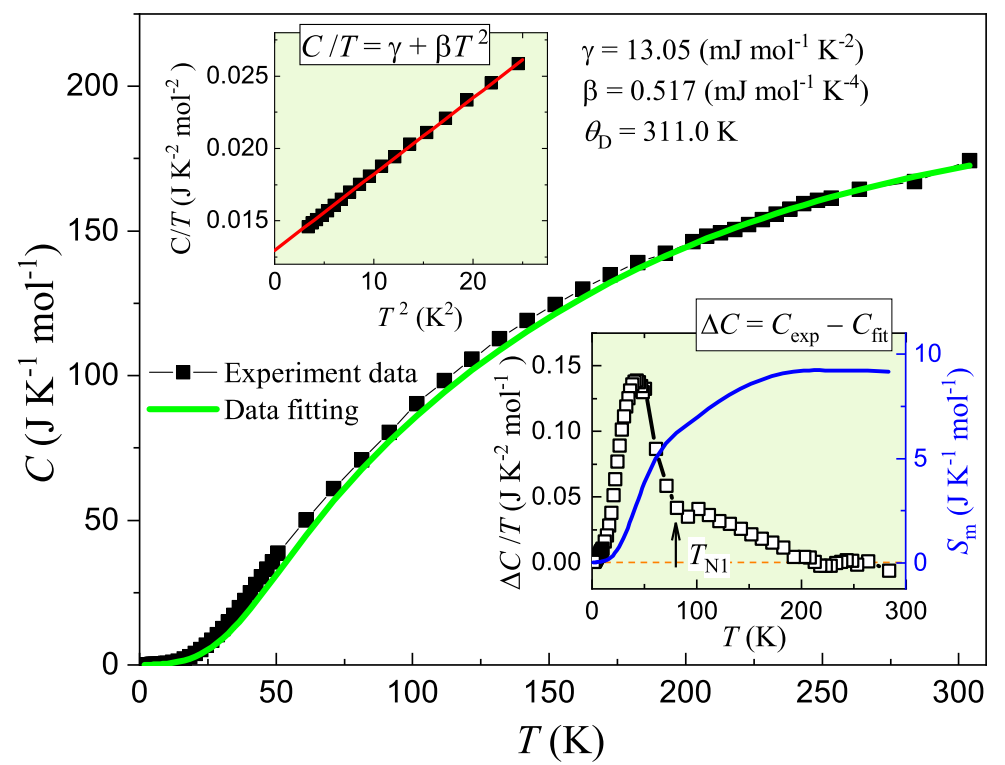

Figure 6. Temperature dependence of specific heat for $\mathrm{Sr}_{2} \mathrm{Cr}_{2} \mathrm{AsO}_{3}$. The upper inset shows the low-temperature specific-heat data, plotted with $C / T$ vs. $T^{2}$. The lower inset plots $\Delta C / T$ (left axis) and the magnetic entropy (right axis) as functions of temperature (see text for the details).

Now we analyze the whole $C(T)$ data, in order to extract the possible magnetic contribution from $\mathrm{Cr}(1)$ spins. Here, the magnetic contribution from $\mathrm{Cr}(2)$ can be ignored, because $T_{\mathrm{N} 2}$ is well above room temperature. Then, similar to our previous treatment [23], the non-magnetic contribution of specific heat can be expressed by:

$$
C=\xi C_{D}+(1-\xi) C_{E}+\gamma T
$$

where $C_{D}=9 N R\left(\frac{T}{\Theta_{\mathrm{D}}}\right)^{3} \int_{0}^{\Theta_{\mathrm{D}} / T} \frac{x^{4} e^{x}}{\left(e^{x}-1\right)^{2}} d x$ and $C_{\mathrm{E}}=3 N R\left(\frac{\Theta_{\mathrm{E}} / T}{e^{\Theta_{\mathrm{E}}} / T}\right)^{2} e^{\Theta_{\mathrm{E}}} / T$ represent the lattice contributions in terms of Debye and Einstein models, respectively. The coefficients, $\xi$ and $(1-\xi)$, describe their individual weights. With $\gamma$ and $\Theta_{\mathrm{D}}$ fixed $\left(13.05 \mathrm{~mJ} \mathrm{~K} \mathrm{~mol}^{-1}\right.$ and $311.0 \mathrm{~K}$, respectively), only two adjust parameters, $\xi$ and $\Theta_{\mathrm{E}}$, were fitted. The data in the range of $10 \leq T \leq 200 \mathrm{~K}$ were dropped in the fitting, because the magnetic contribution cannot be ignored there. As a result, $\Theta_{\mathrm{E}}=668.7 \mathrm{~K}$ and $\xi=0.616$ were yielded. The high $\Theta_{\mathrm{E}}$ value is consistent with the lattice vibrations associated with light (oxygen) atoms and, accordingly, the fitted $\xi$ value is very close to the fraction of heavy-element atoms $(5 / 8)$.

With the fitted data $C_{\text {fit }}$, the magnetic contribution from $\operatorname{Cr}(1)$ spins can be evaluated by the subtraction, $C_{\mathrm{m}}^{\mathrm{Cr} 1} \approx \Delta C=C_{\mathrm{exp}}-C_{\text {fit }}$. The lower inset of Figure 6 plots the temperature dependence of the resulted $\Delta C / T$. The main peak appears below $T_{N 1}=80 \mathrm{~K}$, which is consistent with the magnetic susceptibility measurement. One also sees a long tail extending to $\sim 200 \mathrm{~K}$, indicative of magnetic contributions well above $T_{\mathrm{N} 1}$. This corroborates quasi-2D magnetic correlations/short-range order in the system. The magnetic entropy, $S_{\mathrm{m}}$, can be obtained by the integral $\int_{0}^{T} \frac{C_{\mathrm{m}}}{T} d T$, and the resulted $S_{\mathrm{m}}$ is $9.1 \mathrm{~J} \mathrm{~K}^{-1} \mathrm{~mol}^{-1}$, which is slightly smaller, yet reasonably close to, the expected value of $R \ln (2 S+1)=11.5 \mathrm{~J} \mathrm{~K}^{-1} \mathrm{~mol}^{-1}$ (here $S=3 / 2$ is taken). The result is supported by the theoretical calculations below which shows an ordered moment of $2.52 \mu_{\mathrm{B}}$ for $\mathrm{Cr}(1)$.

\subsection{First-Principles Calculations}

The possible magnetic ground state of $\mathrm{Sr}_{2} \mathrm{Cr}_{2} \mathrm{AsO}_{3}$ was investigated by the DFT-based first-principles calculations. Owing to the complicated crystal structure with both $\mathrm{CrO}_{2}$ planes and CrAs layers, we did not calculate all the combinations of $\mathrm{Cr}$-spin orderings. 
In stead, we took two steps to find out the possible magnetic ground state. First, we focused on the magnetic structure associated with $\operatorname{Cr}(2)$ moments, assuming that $\operatorname{Cr}(1)$ is non-spin-polarized. This is because the magnetic exchange interactions in the $\operatorname{Cr}(2)$ subsystem are expected to be larger due to the higher $T_{\mathrm{N} 2}$ value and, indeed, there is a temperature window which shows AFM order for $\operatorname{Cr}(2)$ and paramagnetism for $\operatorname{Cr}(1)[25,28]$. Second, the whole magnetic structure was optimized by switching on the local spins of $\mathrm{Cr}(1)$. The spin directions were chosen along the crystallographic axes, according to the experimental results of the related compounds [9,11,20,25,28,29].

Table 3 lists the $\mathrm{Cr}$ moments as well as the magnetic energy $E_{\mathrm{m}}$ relative to the nonmagnetic state for different magnetic structures of $\mathrm{Sr}_{2} \mathrm{Cr}_{2} \mathrm{AsO}_{3}$. The first six rows show the results with non-magnetic $\mathrm{Cr}(1)$. Clearly, the in-plane Néel-type antiferromagnetism in the $\mathrm{Cr}(2)$ sublattice shows the lowest magnetic energy. Cr spins tend to align along the $c$ axis. Furthermore, G- and C-type AFM configurations have almost the same magnetic energy (within the calculation accuracy), indicating a very weak interlayer magnetic coupling and, therefore, both magnetic structures are possible. Experimentally, the G-type AFM order exists in $\mathrm{BaCr}_{2} \mathrm{As}_{2}$ [9], $\mathrm{SrCr}_{2} \mathrm{As}_{2}$ [11], $\mathrm{EuCr}_{2} \mathrm{As}_{2}$ [29], and $\mathrm{LaCrAsO}$ [20]. Nevertheless, the C-type AFM order is manifested by $\mathrm{Sr}_{2} \mathrm{Cr}_{3} \mathrm{As}_{2} \mathrm{O}_{2}[25,28]$ and $\mathrm{Ba}_{2} \mathrm{Cr}_{3} \mathrm{As}_{2} \mathrm{O}_{2}$ [25] in which the distance between $\mathrm{CrAs}$ layers is elongated. We thus anticipate that the C-type order is more likely in $\mathrm{Sr}_{2} \mathrm{Cr}_{2} \mathrm{AsO}_{3}$.

Table 3. Calculated magnetic energy $E_{\mathrm{m}}$ (in $\mathrm{meV} /$ f.u.) relative to non-magnetic $(\mathrm{N})$ state and the corresponding magnetic moment $\mu_{\mathrm{Cr}}$ (in $\mu_{\mathrm{B}}$ ) of different magnetic structures of $\mathrm{Sr}_{2} \mathrm{Cr}_{2} \mathrm{AsO}_{3}$. F, S, C, and G denote ferromagnetic, striped AFM, C-type AFM, and G-type AFM structures, respectively. The subscripts $a b$ and $c$ tell the spin directions.

\begin{tabular}{lccc}
\hline Magnetic Structure & $E_{\mathbf{m}}$ & $\mu_{\mathrm{Cr}(1)}$ & $\mu_{\mathrm{Cr}(2)}$ \\
\hline $\operatorname{Cr}(1) \mathrm{N}-\operatorname{Cr}(2) \mathrm{N}$ & 0 & 0 & 0 \\
$\operatorname{Cr}(1) \mathrm{N}-\operatorname{Cr}(2) \mathrm{F}$ & -67.9 & 0 & 1.726 \\
$\operatorname{Cr}(1) \mathrm{N}-\operatorname{Cr}(2) \mathrm{S}$ & -0.5 & 0 & 0.078 \\
$\operatorname{Cr}(1) \mathrm{N}-\operatorname{Cr}(2) \mathrm{C}_{a b}$ & -310.9 & 0 & 2.400 \\
$\operatorname{Cr}(1) \mathrm{N}-\operatorname{Cr}(2) \mathrm{C}_{c}$ & -311.3 & 0 & 2.401 \\
$\operatorname{Cr}(1) \mathrm{N}-\operatorname{Cr}(2) \mathrm{G}_{c}$ & -311.1 & 0 & 2.401 \\
\hline $\operatorname{Cr}(1) \mathrm{F}-\operatorname{Cr}(2) \mathrm{C}_{c}$ & -911.2 & 2.653 & 0.013 \\
$\operatorname{Cr}(1) \mathrm{F}-\operatorname{Cr}(2) \mathrm{C}_{a b}$ & -911.2 & 2.653 & 0.013 \\
\hline $\operatorname{Cr}(1) \mathrm{S}-\operatorname{Cr}(2) \mathrm{C}_{c}$ & -987.3 & 2.590 & 1.085 \\
$\operatorname{Cr}(1) \mathrm{S}-\operatorname{Cr}(2) \mathrm{C}_{a b}$ & -1144.4 & 2.206 & 0.567 \\
\hline $\operatorname{Cr}(1) \mathrm{C}_{c}-\operatorname{Cr}(2) \mathrm{C}_{a b}$ & -1242.8 & 2.529 & 2.417 \\
$\operatorname{Cr}(1) \mathrm{C}_{a b}-\operatorname{Cr}(2) \mathrm{C}_{c}$ & -1249.5 & 2.521 & 2.407 \\
$\operatorname{Cr}(1) \mathrm{C}_{a b}-\operatorname{Cr}(2) \mathrm{C}_{a b}$ & -1251.0 & 2.522 & 2.408 \\
$\operatorname{Cr}(1) \mathrm{C}_{c}-\operatorname{Cr}(2) \mathrm{C}_{c}$ & -1251.7 & 2.522 & 2.409 \\
$\operatorname{Cr}(1) \mathrm{G}_{c}-\operatorname{Cr}(2) \mathrm{C}_{c}$ & -1252.0 & 2.522 & 2.409 \\
\hline
\end{tabular}

The last nine rows in Table 3 present the calculated data for magnetic structures with the C-type magnetic order in CrAs layers. One can find that the $\mathrm{Cr}(1)$ spins also favor an in-plane Néel-type antiferromagnetism with collinear configuration. The Cr-spin direction parallel to $c$ axis is mostly stabilized. Nevertheless, the G-type spin order is slightly favored over the C-type one, although the energy difference is quite small. Note that a similar G-type order appears in $\mathrm{Sr}_{3} \mathrm{Cr}_{2} \mathrm{O}_{7}$ with $\mathrm{CrO}_{2}$ bilayers [48]. Figure 7 depicts the variations of magnetic energy for different magnetic configurations. The most probable magnetic ground 
state is predicted to be a G/C-type AFM for Cr(1) and a C-type AFM for Cr(2) with spins along the $c$ axis. The prediction resembles the experimental results in $\mathrm{Sr}_{2} \mathrm{Cr}_{3} \mathrm{As}_{2} \mathrm{O}_{2}[25,28]$ and $\mathrm{Ba}_{2} \mathrm{Cr}_{3} \mathrm{As}_{2} \mathrm{O}_{2}$ [25].

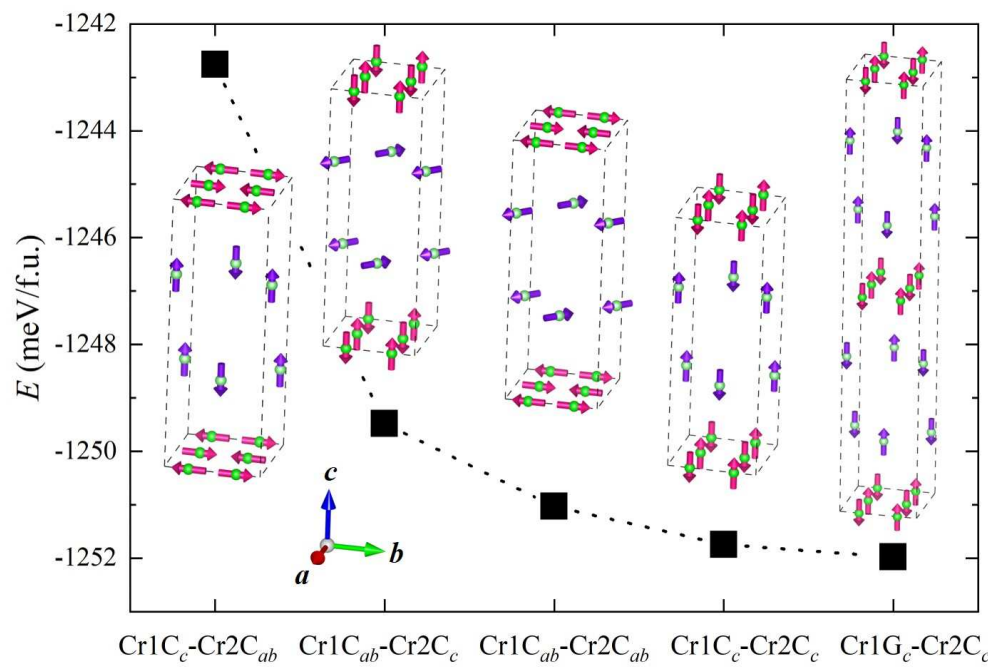

Figure 7. Calculated magnetic energies for the antiferromagnetic states with different spin directions in $\mathrm{Cr}(1)$ (top and bottom) and $\mathrm{Cr}(2)$ (middle) sites of $\mathrm{Sr}_{2} \mathrm{Cr}_{2} \mathrm{AsO}_{3}$.

The ordered moments of $\mathrm{Cr}(1)$ and $\mathrm{Cr}(2)$ are calculated to be 2.52 and $2.41 \mu_{\mathrm{B}}$, respectively. One notes that the magnetic moment of $\mathrm{Cr}(1)$ is reduced by $\sim 0.5 \mu_{\mathrm{B}}$, compared with the $\mathrm{Cr}(1)$ moment of $3.10 \mu_{\mathrm{B}}$ (experimental value [28]) and $2.97 \mu_{\mathrm{B}}$ (theoretical result [23]) in $\mathrm{Sr}_{2} \mathrm{Cr}_{3} \mathrm{As}_{2} \mathrm{O}_{2}$. In the ionic limit, the $\mathrm{Cr}(1)$ moment in the high-spin state would be $\mu_{\mathrm{Cr}}=g S=4(3) \mu_{\mathrm{B}}$ for $\mathrm{Cr}^{2+}\left(\mathrm{Cr}^{3+}\right)$ in $\mathrm{Sr}_{2} \mathrm{Cr}_{3} \mathrm{As}_{2} \mathrm{O}_{2}\left(\mathrm{Sr}_{2} \mathrm{Cr}_{2} \mathrm{AsO}_{3}\right)$, if there were no interlayer charge transfer. The reduction of $\mathrm{Cr}(1)$ moment by $\sim 0.5 \mu_{\mathrm{B}}$ dictates the mixed-valence state as demonstrated above.

To evaluate the charge transfer further, we also performed calculations of the Bader valence charges for different elements in $\mathrm{Sr}_{2} \mathrm{Cr}_{3} \mathrm{As}_{2} \mathrm{O}_{2}$ and $\mathrm{Sr}_{2} \mathrm{Cr}_{2} \mathrm{AsO}_{3}$. The results are presented in Table 4. First, the cations of $\mathrm{Sr}$ and $\mathrm{Cr}$ have less charges, while the anions of As and $\mathrm{O}$ have more charges, compared with corresponding neutral atoms. Second, the Bader charges of the cations (anions) decrease (increase) from $\mathrm{Sr}_{2} \mathrm{Cr}_{3} \mathrm{As}_{2} \mathrm{O}_{2}$ to $\mathrm{Sr}_{2} \mathrm{Cr}_{2} \mathrm{AsO}_{3}$. In particular, the Bader charge of $\mathrm{Cr}(1)$ decreases by 0.6 , suggesting a mixed-valence state for $\mathrm{Cr}(1)$. On the other hand, the Bader charge of $\mathrm{Cr}(2)$ also decreases significantly, consistent with a hole doping in the CrAs layers.

Table 4. Bader charges of different elements in the magnetic ground states of $\mathrm{Sr}_{2} \mathrm{Cr}_{2} \mathrm{AsO}_{3}(2213)$ and $\mathrm{Sr}_{2} \mathrm{Cr}_{3} \mathrm{As}_{3} \mathrm{O}_{2}$ (2322).

\begin{tabular}{lcccc}
\hline \multicolumn{4}{c}{ Bader Charge } \\
\hline Element & $Q_{2213}$ & $Q_{2322}$ & $Q_{2213}-Q_{2322}$ & Neutral \\
\hline Sr & 8.518 & 8.706 & -0.188 & 10 \\
Cr(1) & 10.407 & 11.011 & -0.604 & 12 \\
Cr(2) & 11.396 & 11.619 & -0.223 & 12 \\
As & 16.282 & 16.012 & 0.27 & 15 \\
$\mathrm{O}$ & 7.300 & 7.157 & 0.143 & 6 \\
\hline
\end{tabular}

Figure 8 shows the energy dependence of electronic density of states (DOS) for the C-type AFM state in $\mathrm{Sr}_{2} \mathrm{Cr}_{2} \mathrm{AsO}_{3}$. Both the projected DOS to each element and the total DOS are presented. One sees that the $\mathrm{Cr}$ atoms dominantly contribute the DOS at around the 
Fermi energy $\left(E_{\mathrm{F}}\right)$. Meanwhile, the hybridizations between $\mathrm{Cr}-3 d$ and $\mathrm{O}-2 p$ and between Cr-3d and As- $4 p$ are not negligible (O-2p and As- $4 p$ contribute $12 \%$ and $3 \%$ of the total DOS, respectively). Overall, the DOS profile is quite similar to that of $\mathrm{Sr}_{2} \mathrm{Cr}_{3} \mathrm{As}_{2} \mathrm{O}_{2}$ [23]. The bare DOS at the Fermi level is $N\left(E_{\mathrm{F}}\right)=4.08 \mathrm{eV}^{-1} \mathrm{f} . \mathrm{u} .^{-1}$ based on both spin directions. With the formula of $\gamma_{0}=\frac{1}{3} \pi^{2} k_{B}^{2} N\left(E_{\mathrm{F}}\right)$, we get $\gamma_{0}=11.3 \mathrm{~mJ} \mathrm{~K} \mathrm{~K}^{-2} \mathrm{~mol}^{-1}$. The $\gamma_{0}$ value is close to the electronic specific-heat coefficient above $\left(\gamma=13.05 \mathrm{~mJ} \mathrm{~K}^{-2} \mathrm{~mol}^{-1}\right)$, suggesting relatively weak electron correlations.

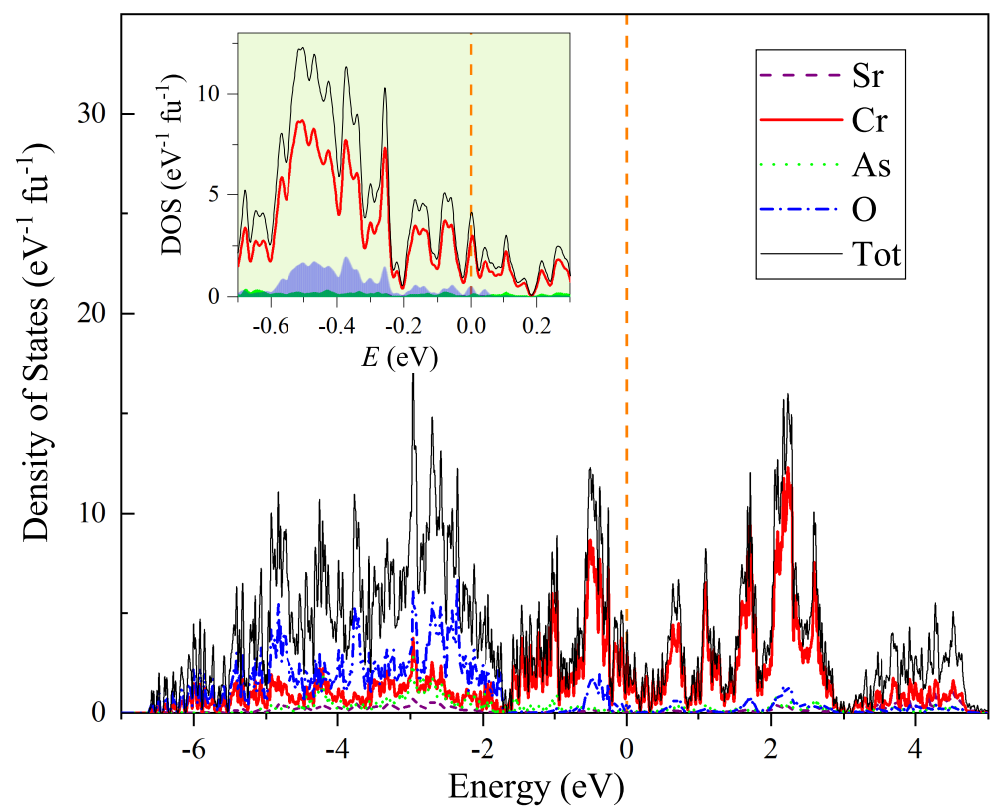

Figure 8. Energy dependence of total and partial electronic density of states (DOS) of the C-type antiferromagnetic state of $\mathrm{Sr}_{2} \mathrm{Cr}_{2} \mathrm{AsO}_{3}$.

As the $\mathrm{Cr}-3 d$ electrons dominate the states at around $E_{\mathrm{F}}$, the DOS was then projected to each $3 d$ orbitals. Figure 9 shows the projected DOS with spin up (positive DOS) and spin down (negative DOS). The contributions of $d_{x z}$ and $d_{y z}$ orbitals are almost degenerate and, for simplicity, the data are combined. For $\mathrm{Cr}(1)$ in the $\mathrm{CrO}_{2}$ planes, $d_{x^{2}-y^{2}}$ and $d_{z^{2}}$ orbitals are almost unoccupied (the DOS weights below $-2 \mathrm{eV}$ are due to the $d-p$ hybridizations). By contrast, the $d_{y z / x z}$ and $d_{x y}$ orbitals are almost single occupied, which gives rise to a magnetic moment close to $3 \mu_{\mathrm{B}}$. The projected DOS at $E_{\mathrm{F}}$ is mostly contributed from $d_{x y}$ orbital. The result can be roughly understood in terms of ionic crystalline electric field (CEF) splitting. $\mathrm{Cr}(1)$ ions are coordinated by five oxygen anions, forming a square pyramid. Under this CEF, the $d_{x^{2}-y^{2}}$ and $d_{z^{2}}$ orbitals are lifted up, thus no electrons fill the two orbitals. On the other hand, the other three orbitals are half filled (see the inset of Figure 9a). One sees that these $d_{x y / y z / x z}$-orbital-related bands are very narrow, suggesting that the $\mathrm{Cr}(1)$ magnetism is basically localized.

The $\mathrm{Cr}(2)$ atoms in the $\mathrm{CrAs}$ layers are coordinated by four arsenic atoms, forming a tetrahedron. The CEF splitting leads to the lift for $d_{x y / y z / x z}$ orbitals. Nevertheless, these three orbitals strongly hybridize with As- $4 p$ electrons, which makes the orbitals effectively occupied with less spin polarizations. On the other hand, the $d_{x^{2}-y^{2}}$ and $d_{z^{2}}$ appear to be basically half filled, which predominately contributes the magnetic moments. The projected DOS at $E_{\mathrm{F}}$ for $\mathrm{Cr}(2)$ mostly comes from the $d_{x^{2}-y^{2}}$ and $d_{y z / x z}$ orbitals. Like the case in other CrAs-layer based materials, the magnetism in the CrAs layers is largely itinerant. 

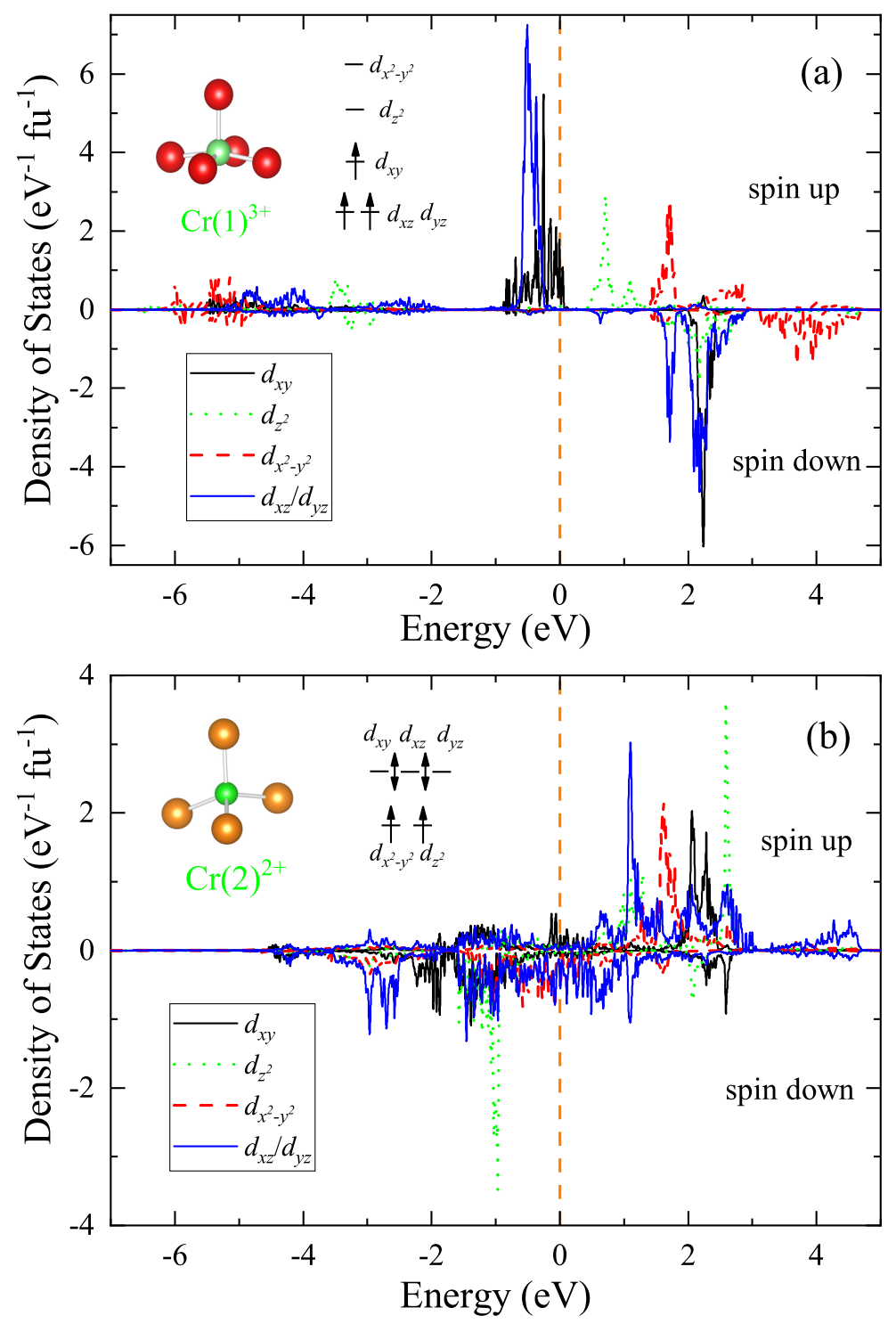

Figure 9. Projected density of states of $3 d$ orbitals of the $\operatorname{Cr}(1)$ at $(1 / 4,1 / 4,0.3116)(\mathbf{a})$ and $\operatorname{Cr}(2)$ at $(1 / 4,3 / 4,0)(b)$ sites in the C-type antiferromagnetic state of $\mathrm{Sr}_{2} \mathrm{Cr}_{2} \mathrm{AsO}_{3}$. The insets show the coordinations of $\mathrm{Cr}(1)$ and $\mathrm{Cr}(2)$ and their corresponding crystalline field splittings.

\section{Concluding Remarks}

In summary, we have synthesized a novel Cr-based oxyarsenide $\mathrm{Sr}_{2} \mathrm{Cr}_{2} \mathrm{AsO}_{3}$, which is comprehensively studied by the structural determination, physical-property measurements, and the first-principles calculations. The new material is an intergrowth of perovskite-like " $\mathrm{Sr}_{3} \mathrm{Cr}_{2} \mathrm{O}_{6}$ " and $\mathrm{ThCr}_{2} \mathrm{Si}_{2}$-type $\mathrm{SrCr}_{2} \mathrm{As}_{2}$, containing both $\mathrm{CrO}_{2}$ planes and CrAs layers. Thus, like the cousin compound $\mathrm{Sr}_{2} \mathrm{Cr}_{3} \mathrm{As}_{2} \mathrm{O}_{2}$, the material bears structural similarities with cuprate and iron-based high-temperature superconductors. Of particular interest in the material is that the $\mathrm{Cr}$ atoms in the two block layers show different formal valences. As a result, an inter-block-layer charge transfer is realized, which effectively dopes holes (electrons) in the $\mathrm{CrAs}\left(\mathrm{CrO}_{2}\right)$ layers. Such a charge-carrier doping is argued to be the main cause for the reduced $T_{\mathrm{N} 2}$ and $T_{\mathrm{N} 1}$. If the AFM Néel temperature in the CrAs layers can be further suppressed by chemical doping and/or applying high pressures, one would expect realization of superconductivity in the system according to the common thread of unconventional superconductors [22].

The title material is demonstrated to be an AFM metal with relatively weak electron correlations. While its CrAs layers show an AFM order at $T_{\mathrm{N} 2}=420 \mathrm{~K}$, the $\mathrm{CrO}_{2}$ planes exhibit a quasi-2D magnetism with long-range spin ordering below $T_{\mathrm{N} 2}=80 \mathrm{~K}$. At low 
temperatures, a re-entrant magnetic transitions with a huge magnetic hysteresis shows up, reflecting complex interactions among $\mathrm{Cr}(1)$ and $\mathrm{Cr}(2)$ spins and conduction electrons. Our first-principles calculations predict C-type AFM order in the CrAs layers together with Cor G-type AFM order in the $\mathrm{CrO}_{2}$ planes. Future study with neutron diffraction is called for to verify the magnetic structure and to clarify the re-entrant magnetic transition.

Author Contributions: Conceptualization, H.J. and G.-H.C.; methodology, all authors; software, H.J.; validation, all authors; formal analysis, Y.-Q.L., H.J. and G.-H.C.; investigation, Y.-Q.L., H.J., H.-X.L., S.-J.S., S.-Q.W. and Z.R.; resources, Z.R. and G.-H.C.; data curation, Y.-Q.L.; writing-original draft preparation, Y.-Q.L.; writing—review and editing, G.-H.C.; visualization, Y.-Q.L., H.J. and G.-H.C.; supervision, G.-H.C.; project administration, G.-H.C.; funding acquisition, G.-H.C. All authors have read and agreed to the published version of the manuscript.

Funding: This work was supported by the National Natural Science Foundation of China (12005003), the National Key R\&D Program of China (2017YFA0303002), and the Key R\&D Program of Zhejiang Province, China (2021C01002).

Institutional Review Board Statement: Not applicable.

Informed Consent Statement: Not applicable.

Data Availability Statement: The datasets used and/or analyzed during the current study are available from the corresponding author on reasonable request.

Conflicts of Interest: The authors declare no conflict of interest.

\section{References}

1. Wu, W.; Cheng, J.; Matsubayashi, K.; Kong, P.; Lin, F.; Jin, C.; Wang, N.; Uwatoko, Y.; Luo, J. Superconductivity in the vicinity of antiferromagnetic order in CrAs. Nat. Commun. 2014, 5, 5508. [CrossRef]

2. Kotegawa, H.; Nakahara, S.; Tou, H.; Sugawara, H. Superconductivity of $2.2 \mathrm{~K}$ under Pressure in Helimagnet CrAs. J. Phys. Soc. Jpn. 2014, 83, 093702. [CrossRef]

3. Bao, J.K.; Liu, J.Y.; Ma, C.W.; Meng, Z.H.; Tang, Z.T.; Sun, Y.L.; Zhai, H.F.; Jiang, H.; Bai, H.; Feng, C.M.; et al. Superconductivity in Quasi-One-Dimensional $\mathrm{K}_{2} \mathrm{Cr}_{3} \mathrm{As}_{3}$ with Significant Electron Correlations. Phys. Rev. X 2015, 5, 011013. [CrossRef]

4. Tang, Z.T.; Bao, J.K.; Liu, Y.; Sun, Y.L.; Ablimit, A.; Zhai, H.F.; Jiang, H.; Feng, C.M.; Xu, Z.A.; Cao, G.H. Unconventional superconductivity in quasi-one-dimensional $\mathrm{Rb}_{2} \mathrm{Cr}_{3} \mathrm{As}_{3}$. Phys. Rev. B 2015, 91, 020506. [CrossRef]

5. Tang, Z.T.; Bao, J.K.; Wang, Z.; Bai, H.; Jiang, H.; Liu, Y.; Zhai, H.F.; Feng, C.M.; Xu, Z.A.; Cao, G.H. Superconductivity in quasi-one-dimensional $\mathrm{Cs}_{2} \mathrm{Cr}_{3} \mathrm{As}_{3}$ with large interchain distance. Sci. China Mater. 2015, 58, 16-20. [CrossRef]

6. Edelmann, M.; Sangiovanni, G.; Capone, M.; de' Medici, L. Chromium analogs of iron-based superconductors. Phys. Rev. B 2017, 95, 205118. [CrossRef]

7. Wang, W.S.; Gao, M.; Yang, Y.; Xiang, Y.Y.; Wang, Q.H. Possible superconductivity in the electron-doped chromium pnictide LaOCrAs. Phys. Rev. B 2017, 95, 144507. [CrossRef]

8. Pizarro, J.M.; Calderón, M.J.; Liu, J.; Muñoz, M.C.; Bascones, E. Strong correlations and the search for high- $T_{\mathcal{C}}$ superconductivity in chromium pnictides and chalcogenides. Phys. Rev. B 2017, 95, 075115. [CrossRef]

9. Filsinger, K.A.; Schnelle, W.; Adler, P.; Fecher, G.H.; Reehuis, M.; Hoser, A.; Hoffmann, J.U.; Werner, P.; Greenblatt, M.; Felser, C. Antiferromagnetic structure and electronic properties of $\mathrm{BaCr}_{2} \mathrm{As}_{2}$ and $\mathrm{BaCrFeAs}_{2}$. Phys. Rev. B 2017, 95, 184414. [CrossRef]

10. Richard, P.; van Roekeghem, A.; Lv, B.Q.; Qian, T.; Kim, T.K.; Hoesch, M.; Hu, J.P.; Sefat, A.S.; Biermann, S.; Ding, H. Is BaCr 2 As 2 symmetrical to $\mathrm{BaFe}_{2} \mathrm{As}_{2}$ with respect to half $3 d$ shell filling? Phys. Rev. B 2017, 95, 184516. 184516. [CrossRef]

11. Das, P.; Sangeetha, N.S.; Lindemann, G.R.; Heitmann, T.W.; Kreyssig, A.; Goldman, A.I.; McQueeney, R.J.; Johnston, D.C.; Vaknin, D. Itinerant G-type antiferromagnetic order in $\mathrm{SrCr}_{2} \mathrm{As}_{2}$. Phys. Rev. B 2017, 96, 014411. [CrossRef]

12. Mu, Q.G.; Ruan, B.B.; Pan, B.J.; Liu, T.; Yu, J.; Zhao, K.; Chen, G.F.; Ren, Z.A. Superconductivity at 5 K in quasi-one-dimensional Cr-based $\mathrm{KCr}_{3} \mathrm{As}_{3}$ single crystals. Phys. Rev. B 2017, 96, 140504. [CrossRef]

13. Mu, Q.G.; Ruan, B.B.; Pan, B.J.; Liu, T.; Yu, J.; Zhao, K.; Chen, G.F.; Ren, Z.A. Ion-exchange synthesis and superconductivity at 8.6 $\mathrm{K}$ of $\mathrm{Na}_{2} \mathrm{Cr}_{3} \mathrm{As}_{3}$ with quasi-one-dimensional crystal structure. Phys. Rev. Mater. 2018, 2, 034803. [CrossRef]

14. Wu, W.; Liu, K.; Li, Y.; Yu, Z.; Wu, D.; Shao, Y.; Na, S.; Li, G.; Huang, R.; Xiang, T.; et al. Superconductivity in chromium nitrides $\mathrm{Pr}_{3} \mathrm{Cr}_{10-x} \mathrm{~N}_{11}$ with strong electroncorrelations. Natl. Sci. Rev. 2019, 7, 21-26. [CrossRef]

15. Cai, W.; Sun, H.; Xia, W.; Wu, C.; Liu, Y.; Liu, H.; Gong, Y.; Yao, D.X.; Guo, Y.; Wang, M. Pressure-induced superconductivity and structural transition in ferromagnetic CrSiTe 3 . Phys. Rev. B 2020, 102, 144525. [CrossRef]

16. Duan, L.; Wang, X.; Zhan, F.; Zhang, J.; Hu, Z.; Zhao, J.; Li, W.; Cao, L.; Deng, Z.; Yu, R.; et al. High-pressure synthesis, crystal structure and physical properties of a new Cr-based arsenide $\mathrm{La}_{3} \mathrm{CrAs}_{5}$. Sci. China Mater. 2020, 63, 1750-1758. [CrossRef]

17. Pfisterer, M.; Nagorsen, G. Zur struktur ternärer übergangsmetallarsenide/on the structure of ternary arsenides. Z. Naturforschung B 1980, 35, 703-704. [CrossRef] 
18. Singh, D.J.; Sefat, A.S.; McGuire, M.A.; Sales, B.C.; Mandrus, D.; VanBebber, L.H.; Keppens, V. Itinerant antiferromagnetism in $\mathrm{BaCr}_{2} \mathrm{As}_{2}$ : Experimental characterization and electronic structure calculations. Phys. Rev. B 2009, 79, 094429. [CrossRef]

19. Paramanik, U.B.; Prasad, R.; Geibel, C.; Hossain, Z. Itinerant and local-moment magnetism in $\mathrm{EuCr}_{2} \mathrm{As}_{2}$ single crystals. Phys. Rev. B 2014, 89, 144423. [CrossRef]

20. Park, S.W.; Mizoguchi, H.; Kodama, K.; Shamoto, S.I.; Otomo, T.; Matsuishi, S.; Kamiya, T.; Hosono, H. Magnetic Structure and Electromagnetic Properties of $\mathrm{LnCrAsO}$ with a $\mathrm{ZrCuSiAs}$-type Structure ( $\mathrm{Ln}=\mathrm{La}, \mathrm{Ce}, \mathrm{Pr}$, and $\mathrm{Nd})$. Inorg. Chem. 2013, 52, 13363-13368. [CrossRef]

21. Kamihara, Y.; Watanabe, T.; Hirano, M.; Hosono, H. Iron-Based Layered Superconductor $\mathrm{La}\left[\mathrm{O}_{1-x} \mathrm{~F}_{x}\right] \mathrm{Fe} \mathrm{As}(x=0.05-0.12)$ with $T_{c}=26$ K. J. Am. Chem. Soc. 2008, 130, 3296. [CrossRef]

22. Scalapino, D.J. A common thread: The pairing interaction for unconventional superconductors. Rev. Mod. Phys. 2012, 84, 1383-1417. [CrossRef]

23. Jiang, H.; Bao, J.K.; Zhai, H.F.; Tang, Z.T.; Sun, Y.L.; Liu, Y.; Wang, Z.C.; Bai, H.; Xu, Z.A.; Cao, G.H. Physical properties and electronic structure of $\mathrm{Sr}_{2} \mathrm{Cr}_{3} \mathrm{As}_{2} \mathrm{O}_{2}$ containing $\mathrm{CrO}_{2}$ and $\mathrm{Cr}_{2} \mathrm{As}_{2}$ square-planar lattices. Phys. Rev. B 2015, 92, 205107. [CrossRef]

24. Ablimit, A.; Sun, Y.L.; Jiang, H.; Bao, J.K.; Zhai, H.F.; Tang, Z.T.; Liu, Y.; Wang, Z.C.; Feng, C.M.; Cao, G.H. Synthesis, crystal structure and physical properties of a new oxypnictide $\mathrm{Ba}_{2} \mathrm{Ti}_{2} \mathrm{Cr}_{2} \mathrm{As}_{4} \mathrm{O}$ containing $\left[\mathrm{Ti}_{2} \mathrm{As}_{2} \mathrm{O}\right]^{2-}$ and $\left[\mathrm{Cr}_{2} \mathrm{As}_{2}\right]^{2-}$ layers. J. Alloys Compd. 2017, 694, 1149-1153. [CrossRef]

25. Xu, X.; Jones, M.A.; Cassidy, S.J.; Manuel, P.; Orlandi, F.; Batuk, M.; Hadermann, J.; Clarke, S.J. Magnetic Ordering in the Layered $\mathrm{Cr}$ (II) Oxide Arsenides $\mathrm{Sr}_{2} \mathrm{CrO}_{2} \mathrm{Cr}_{2} \mathrm{As}_{2}$ and $\mathrm{Ba}_{2} \mathrm{CrO}_{2} \mathrm{Cr}_{2} \mathrm{As}_{2}$. Inorg. Chem. 2020, 59, 15898-15912. [CrossRef]

26. Naik, S.P.K.; Iwasa, Y.; Kuramochi, K.; Ichihara, Y.; Kishio, K.; Hongo, K.; Maezono, R.; Nishio, T.; Ogino, H. Synthesis, Electronic Structure, and Physical Properties of Layered Oxypnictides $\mathrm{Sr}_{2} \mathrm{ScCrAsO}_{3}$ and $\mathrm{Ba}_{3} \mathrm{Sc}_{2} \mathrm{Cr}_{2} \mathrm{As}_{2} \mathrm{O}_{5}$. Inorg. Chem. 2021, 60, 1930-1936. [CrossRef]

27. Jiang, H.; Sun, Y.L.; Xu, Z.A.; Cao, G.H. Crystal chemistry and structural design of iron-based superconductors. Chin. Phys. B 2013, 22, 087410. [CrossRef]

28. Liu, J.; Wang, J.; Sheng, J.; Ye, F.; Taddei, K.M.; Fernandez-Baca, J.A.; Luo, W.; Sun, G.A.; Wang, Z.C.; Jiang, H.; et al. Neutron diffraction study on magnetic structures and transitions in $\mathrm{Sr}_{2} \mathrm{Cr}_{3} \mathrm{As}_{2} \mathrm{O}_{2}$. Phys. Rev. B 2018, 98, 134416. [CrossRef]

29. Nandi, S.; Xiao, Y.; Qureshi, N.; Paramanik, U.B.; Jin, W.T.; Su, Y.; Ouladdiaf, B.; Hossain, Z.; Brückel, T. Magnetic structures of the Eu and $\mathrm{Cr}$ moments in $\mathrm{EuCr}_{2} \mathrm{As}_{2}$ : Neutron diffraction study. Phys. Rev. B 2016, 94, 094411. [CrossRef]

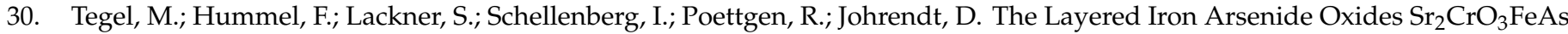
and $\mathrm{Ba}_{2} \mathrm{ScO}_{3} \mathrm{FeAs}$. Z. Anorg. Und Allg. Chem. 2009, 635, 2242-2248. [CrossRef]

31. Ogino, H.; Katsura, Y.; Horii, S.; Kishio, K.; Shimoyama, J.I. New iron-based arsenide oxides $\left(\mathrm{Fe}_{2} \mathrm{As}_{2}\right)\left(\mathrm{Sr}_{4} M_{2} \mathrm{O}_{6}\right)\left(M_{=} \mathrm{Sc}, \mathrm{Cr}\right)$. Supercond. Sci. Technol. 2009, 22, 085001. [CrossRef]

32. Zhu, W.; Hor, P. $\mathrm{Sr}_{2} \mathrm{CuGaO}_{3} \mathrm{~S}$, a Rare Example of Square Pyramidal Gallium. Inorg. Chem. 1997, 36, 3576-3577. [CrossRef]

33. Rodríguez-Carvajal, J. Recent advances in magnetic structure determination by neutron powder diffraction. Phys. B Condens. Matter 1993, 192, 55-69. [CrossRef]

34. Perdew, J.P.; Burke, K.; Ernzerhof, M. Generalized Gradient Approximation Made Simple. Phys. Rev. Lett. 1996, 77, 3865-3868. [CrossRef]

35. Kresse, G.; Furthmüller, J. Efficient iterative schemes for ab initio total-energy calculations using a plane-wave basis set. Phys. Rev. B 1996, 54, 11169-11186. [CrossRef]

36. Wang, Z.; Wu, S.; Ji, L.; Cao, G. Block-layer model for intergrowth structures. Nano Res. 2021, 14, 3629-3635. [CrossRef]

37. Brown, I.D.; Altermatt, D. Bond-valence parameters obtained from a systematic analysis of the Inorganic Crystal Structure Database. Acta Crystallogr. Sec. B 1985, 41, 244-247. [CrossRef]

38. White, G.K.; Woods, S. Electrical and thermal resistivity of the transition elements at low temperatures. Philos. Trans. R. Soc. London. Ser. A Math. Phys. Sci. 1959, 251, 273-302. [CrossRef]

39. Ziman, J.M. Electrons and Phonons; Clarendon Press: Oxford, UK, 1960.

40. Mott, N.F. Electrons in transition metals. Adv. Phys. 1964, 13, 325-422. [CrossRef]

41. Ishikawa, A. Electrical Resesrivity Due to Antiferromagnetic Spin Waves in Cr. J. Phys. Soc. Jpn. 1982, 51, 441-451. [CrossRef]

42. Lumsden, M.D.; Sales, B.C.; Mandrus, D.; Nagler, S.E.; Thompson, J.R. Weak Ferromagnetism and Field-Induced Spin Reorientation in $\mathrm{K}_{2} \mathrm{~V}_{3} \mathrm{O}_{8}$. Phys. Rev. Lett. 2001, 86, 159-162. [CrossRef] [PubMed]

43. McGuire, M.A.; Garlea, V.O.; Kc, S.; Cooper, V.R.; Yan, J.; Cao, H.; Sales, B.C. Antiferromagnetism in the van der Waals layered spin-lozenge semiconductor CrTe 3 . Phys. Rev. B 2017, 95, 144421. [CrossRef]

44. Clement, R.; Girerd, J.; Morgenstern-Badarau, I. Dramatic modification of the magnetic properties of lamellar manganese trithiophosphonite $\mathrm{MnPS}_{3}$ upon intercalation. Inorg. Chem. 1980, 19, 2852-2854. [CrossRef]

45. Chen, H.; McClain, R.; He, J.; Zhang, C.; Olding, J.N.; Dos Reis, R.; Bao, J.K.; Hadar, I.; Spanopoulos, I.; Malliakas, C.D.; et al. Antiferromagnetic Semiconductor BaFMn 0.5 Te with Unique Mn Ordering and Red Photoluminescence. J. Am. Chem. Soc. 2019, 141, 17421-17430. [CrossRef] [PubMed]

46. Zhu, W.; Hor, P. Crystal Structure of New Layered Oxysulfides: $\mathrm{Sr}_{3} \mathrm{Cu}_{2} \mathrm{Fe}_{2} \mathrm{O}_{5} \mathrm{~S}_{2}$ and $\mathrm{Sr}_{2} \mathrm{CuMO}_{3} \mathrm{~S}$ (M=Cr, Fe, In). J. Solid State Chem. 1997, 134, 128-131. [CrossRef]

47. de Gennes, P.G. Effects of Double Exchange in Magnetic Crystals. Phys. Rev. 1960, 118, 141-154. 118.141. [CrossRef] 
48. Jeanneau, J.; Toulemonde, P.; Remenyi, G.; Sulpice, A.; Colin, C.; Nassif, V.; Suard, E.; Salas Colera, E.; Castro, G.R.; Gay, F.; et al. Singlet Orbital Ordering in Bilayer $\mathrm{Sr}_{3} \mathrm{Cr}_{2} \mathrm{O}_{7}$. Phys. Rev. Lett. 2017, 118, 207207. [CrossRef] 